Pensamiento Crítico N. ${ }^{\circ}$ 9, pp. 107-113

\title{
El marketing y la ciencia
}

\author{
Mg. Víctor Eduardo Orozco Livia
}

\section{RESUMEN}

En los tiempos actuales de globalización y dificultades de desarrollo del socialismo, existe una excesiva valoración de ciertos instrumentos técnicos de negociación.

El Marketing es presentado y difundido como ciencia, pese a que no reúne los requisitos para ser considerado como ciencia. En las apreciaciones de la filosofía que razona con los conocimientos probados por la ciencia, el Marketing es técnica y depende de los lineamientos explicativos de la ciencia económica.

Palabras clave: Ciencia, Técnica, Marketing, Filosofía, Pragmatismo.

\section{ABSTRACT}

In the current times of globalization and difficulties of development of the socialism, there exists an excessive valuation of certain technical instruments of negotiation.

The marketing is presented and spread as science in spite of that it does not re-join the requirements to be considered as a science.

In the appraisals of the philosophy that reasons with the knowledge proved by the science, the marketing is technical and depends on the guidelines of the economic science.

Keywords: Science, technique, marketing, philosophy, pragmatism. 


\section{Víctor Eduardo Orozco Livia}

En las últimas décadas, se han publicado una serie de libros y artículos referidos al Marketing como ciencia. Así, por ejemplo, un especialista del comercio empresarial, Juan Aragay Prades, en un artículo que publica en la Enciclopedia de la Mercadotecnia, dice: “... el Marketing en su constante evolución de moderna ciencia en desarrollo, ha ido tratando de encontrar en las últimos años una solución que basada en los principios científicos fuera lo suficientemente realizable y efectiva para llevar a la práctica, de una manera constante y metódica el diagnóstico comercial permanente de nuestra empresa y del mercado, que nos permita tenerlo siempre al día para muestra constante toma de decisiones" ${ }^{1}$. Un economista con renombre como Peter Drucker, opina también que el mercado es posiblemente la única disciplina de los negocios que pude llamarse verdaderamente científica.

En un artículo publicado en la Revista Harvard Business Review, vol. 81, del año 2003, titulada "El Marketing Óptimo", se vuelve a insistir en la necesidad de "Aplicar la ciencia del Marketing" en los negocios ${ }^{2}$.

No todos, sin embargo, están de acuerdo en reconocer al Marketing como ciencia, consideran que es una técnica, técnica de comercialización.

Para dilucidar este asunto, de que si el Marketing es ciencia o técnica, primero tenemos que determinar què es ciencia y luego hurgar en los aspectos del Marketing para saber si cumple con los requisitos de la ciencia.

\section{CIENCIA}

Para el filósofo Julio Sanz, la ciencia es "teoría controlada por la observación"3. En otros términos, la ciencia es una explicación del comportamiento de la realidad; y, en base a ello, se puede ejercer un control sobre dicha realidad. Y agrega que las funciones de la ciencia son la descripción, la explicación, la predicción y la aplicación científica. Los que constituyen también requisitos para determinar si una argumentación es ciencia o no.

1 Aragay, Juan. "Análisis comercial de la empresa". En: Enciclopedia de la Mercadotecnia. Barcelona, Edit. Nauta, 1979, p. 126.

2 Corstgan, Marcel y Jeffrey Merrihue. Rev. Cit., p. 228.

3 Sanz, Julio. Introducción a la ciencia. Lima, Edit. Amaru, 1987, p. 28. 


\section{El marketing y la ciencia}

Para hacer ciencia se requiere investigar, es decir, describir primero y luego razonar con tal información para descubrir propiedades de causa a efecto en la realidad que explican su comportamiento. De las formas externas al contenido de la realidad es el recorrido del pensamiento cognoscitivo para hacer teoría o discurso explicativo científico. No es este, sin embargo, el recorrido que reconoce para el conocimiento, la filosofía del Pragmatismo, que es la que apoya a la teoría convencional moderna sobre los negocios.

La filosofía nos dice que -por lo menos- tres asuntos deben aclararse para poder hacer ciencia. El problema de la realidad, el método racional y el problema de la verdad.

Dice William James, el fundador del Pragmatismo, que "Por realidades" u "objetos", entendemos aquí cosas del sentido común, sensiblemente presentes, o bien relaciones de sentido común tales como fecha, lugares, distancias, géneros, actividades" 4 . Es decir, para James, lo captado por los sentidos constituye la realidad o esta es una idea que se forma en la mente por lo percibido por el sentido común. No considera el Pragmatismo a la realidad con existencia propia, independientemente de ser captada o no por los sentidos. Para abreviar, el Pragmatismo afirma que la realidad es la idea que se tiene sobre los objetos.

En lo que respecta a la verdad, dice William James: "El valor práctico de las ideas verdaderas deriva, pues, primariamente de la importancia práctica de sus objetos para nosotros" ${ }^{5}$. Es decir, la idea eficaz que se utilice para una ocasión es la verdadera. En la mente, dice el Pragmatismo, existen otras ideas abstractas derivadas de la lógica, pero solo la que es útil en una circunstancia es la verdadera. Las otras -según el Pragmatismo- esperan su oportunidad para ser útiles o verdaderas.

La lógica de la que habla William James es la lógica formal, de razonamiento deductivo, que dice, se hizo científica por los aportes de los filósofos Schiller y Dewey. Al respecto, dice John Dewey: "lo que necesitamos ahora es una lógica unificada que tome en cuenta el movimiento de vaivén entre el sentido común y la ciencia"6.

4 James William. Pragmatismo. México, Edit. Roble, 1963, p. 130.

5 James, William. Ob. Cit., p. 129.

6 Dewey, John. Lógica. México, FCE, 1950, p. 114. 


\section{Víctor Eduardo Orozco Livia}

En los términos del Pragmatismo, la ciencia se construye por razonamientos deductivos con lo captado por el sentido común. Pero esta lógica planteada por Dewey discurre entre ideas para arribar a una conclusión que es también otra idea. No toma en cuenta representaciones de la realidad, porque la realidad, para el Pragmatismo, es la idea de sentido común. Así, el recorrido del razonamiento deductivo del Pragmatismo es de ideas a ideas para la construcción de la ciencia y la realidad no aparece por ningún lado.

Difícilmente, podría aceptarse que este movimiento racional sea capaz de hacer ciencia. Para hacer ciencia, el pensamiento cognoscitivo tiene que partir de un razonamiento inductivo con representaciones de la realidad, luego la conclusión de la inducción se debe constituir en la primera premisa de la deducción. Así, el raciocinio no se aparta en ningún momento de la realidad y puede arribar a conclusiones de conocimientos nuevos. Solo con deducción -decía Stuar Mill- no se arriba a un nuevo conocimiento, por que la conclusión de la deducción no rebasa lo que se afirma en la primera premisa.

Las exigencias para hacer ciencia son mayores, se requiere de raciocinios con representaciones de la realidad, que no se limitan a la inducción y la deducción, para elaborar un cuerpo teórico explicativo del comportamiento de la realidad. Si los raciocinios conducen a una explicación que puede ser probada, en base a esas propiedades, se podrían hacer proyecciones o predicciones que permitan la toma de decisiones. Por ejemplo, si existe inflación, hurgamos en las interioridades de la inflación para saber sus causas; conocidas estas, podemos prescribir sus tendencias, para luego aplicar medidas para su contención. Tal es el ejercicio de la ciencia.

\section{EL MARKETING}

Para un experto en la mercadotecnia como Konrad Fisher Rossi, ex Director Académico de ESAN, "el nuevo concepto de mercadeo se basa en la satisfacción de los deseos y necesidades del consumidor. Por cierto que no por razones filantrópicas si no que -feliz coincidencia- por ser la mejor política que se puede seguir para lograr el máximo rendimiento de una inversión"7.

$7 \quad$ Fisher, Konrad. Mercadotecnia. Lima, Edit. Del Mañana, 1982, p. 18. 


\section{El marketing y la ciencia}

Es decir, el Marketing forma parte del proceso de comercialización de mercancías que es -por cierto- materia de estudio de la ciencia económica en su acápite de la realización de la mercancía. Para la ciencia económica, la necesidad de la realización de las mercancías es para convertir el capital constante, el capital variable y el trabajo no pagado al asalariado en dinero. Un dinero incrementado con respecto al capital inicialmente invertido debido a la parte de la jornada no remunerada al trabajador. Es el contenido de la realización de las mercancías a cuyo objetivo contribuye el Marketing procurando se lleve a cabo con la mayor eficiencia y prontitud. Así, el Marketing opera bajo los criterios científicos de la comercialización.

Si la confusión es grande entre los que claman por el Marketing como ciencia es porque ésta se apoya, fundamentalmente, en la estadística, que a su vez es de empleo necesario en todo trabajo de investigación. Y en efecto, el Marketing es -sobre todoinvestigación de mercados con el empleo de la estadística.

Dice Fisher: "De un modo general podemos definir las investigaciones de mercados como el proceso de recopilación, ordenamiento y análisis de todos los datos sobre problemas relacionados con la transferencia y ventas de bienes y servicios desde el productor hasta el consumidor" 8 .

El Marketing emplea la estadística como lo emplea también el procedimiento de investigación para describir la realidad. La diferencia en el uso de la estadística entre el Marketing y la ciencia, es que la primera pasa a tomar decisiones desde la descripción de los hechos, y la ciencia la emplea, preliminarmente, para arribar a datos ordenados que le permitan razonar, para arribar a una explicación. Tal explicación le permite predecir; $y$, con predicción, se pueden hacer anticipaciones con medidas que cambien el rumbo de los hechos para alcanzar objetivos propuestos.

El Marketing se salta el requisito de la explicación o la respuesta al porqué de los hechos y es por ello que la lucidez de Konrad Fisher le hace decir que: "Una de las desventajas del método estadístico es que no permite probar la relaciones de causa a

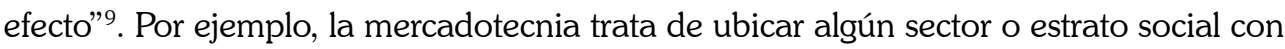
determinado nivel de ingresos, compatible con el precio del bien que ofrece, y si la competencia es escasa en ese estrato social, el Marketing puede hacer suyo ese "nicho".

8 Fisher, Konrad. Ob. cit., p. 85.

9 Fisher, Konrad. Ob. cit., p. 91. 


\section{Víctor Eduardo Orozco Livia}

No es objetivo del Marketing determinar porqué un sector o estrato social tiene el promedio de ingresos que presenta o porqué otros tienen otros niveles de ingresos. La estadística por el objetivo descriptivo que persigue se desentiende del porqué de esas diferencias de ingresos y menos aún le interesa de donde provienen los ingresos. Tales ingredientes de Marketing lo ubican, por ello, en el terreno de la técnica. La técnica "se parece a la episteme porque implica el conocimientos de principios, pero difiere de ella por que su fin no es la comprensión desinteresada, sino el hacer o fabricar algo" ${ }^{10}$.

\section{LA APOLOGÍA DE MARKETING COMO CIENCIA}

El Marketing no reúne requisitos para ser considerada como ciencia. Solo responde al cómo debería convertirse la mercancía en dinero con eficiencia y rapidez, y ello lo ubica en el terreno de la técnica.

La ciencia económica en su acápite de la realización de la mercancía, exige que se responda al porqué de la necesidad de la transformación de la mercancía en dinero y solo con lo cual puede operar el Marketing.

Si existen entusiastas por la globalización como Peter Drucker, que creen que el Marketing es ciencia, es porque en sus razonamientos se aproximan a lo que dice Francis Fukuyama, que se vive la época del triunfo total de los negocios en el mundo y que ramas inherentes a ellos -como el Marketing-deben ser reconocidas como ciencia. Es la concepción filosófica del Pragmatismo la que apoya estos argumentos. El Pragmatismo, con su fundador William James a la cabeza, se inspira en el mundo de los negocios para discernir sobre la verdad en términos filosóficos. Dice James, por ejemplo: "De hecho, la verdad descansa, en su mayor parte en un sistema de crédito. Nuestros pensamientos y creencias pasan en tanto haya nadie que los desafíe, del mismo modo que pase un billete de banco en tanto que nadie lo rehúse" ${ }^{11}$. Pareciera que está hablando un empresario tratando de hacer filosofía sobre la verdad, pero resulta que es un filósofo el que se ocupa de la verdad. La filosofía no obstante no es tan estrecha, se ocupa de las propiedades generales del ser o de grandes sectores componentes del mundo, razonando con los aportes probados por la ciencia para arribar a generalizaciones.

10 Runes, Dagoberto. Diccionario de filosofía. México, Edit. Grijalbo, 1969, p. 363.

11 James, William. Ob. cit., p. 131. 


\section{El marketing y la ciencia}

En definitiva, el Marketing es técnica y no ciencia; y como dicen los filósofos, la técnica es el instrumento de acción de la teoría.

\section{BIBLIOGRAFÍA}

Arce Carrascozo, J. L. (1999). Teoría del conocimiento. Ed. Síntesis. Madrid.

Conforth, Maurice (1960). Ciencia versus Idealismo. Buenos Aires: Ed. Lautaro.

Stanton, William (1995). Fundamentos de marketing. México: Edit. Mc Graw Hill.

Morin, Edgar (1986). El método. Madrid: Ed. Cátedra. 